\title{
Environmental evolution of Xingkai (Khanka) Lake since 200 ka by OSL dating of sand hills
}

\author{
ZHU Yun ${ }^{1,2}$, SHEN Ji $^{1 *}$, LEI GuoLiang ${ }^{2}$ \& WANG Yong ${ }^{1}$ \\ ${ }^{1}$ Key Laboratory of Lake Science and Environment, Nanjing Institute of Geography and Limnology, Chinese Academy of Sciences, Nanjing \\ 210008, China; \\ ${ }^{2}$ College of Geographical Sciences, Fujian Normal University, Fujian Key Laboratory of Subtropical Resources and Environment, Fuzhou \\ 350007, China
}

Received February 28, 2011; accepted May 13, 2011

\begin{abstract}
Crossing the Sino-Russian boundary, Xingkai Lake is the largest freshwater lake in Northeast Asia. In addition to the lakeshore, there are four sand hills on the north side of the lake that accumulated during a period of sustainable and stable lacustrine transgression and were preserved after depression. Analysis of well-dated stratigraphic sequences based on 18 OSL datings combined with multiple index analysis of six sites in the sand hills revealed that the north shoreline of Xingkai Lake retreated in a stepwise fashion since the middle Pleistocene, and that at least four transgressions (during 193-183 ka, 136-130 ka, 24-15 ka and since 3 ka) and three depressions occurred during this process. The results of this study confirmed that transgressive stages were concurrent with epochs of climate cooling, whereas the period of regression corresponded to the climatic optima. Transgressions and regressions were primarily caused by variations in the intensity of alluvial accumulation in the Ussuri River Valley and fluctuations in regional temperature and humidity that were controlled by climatic change. Moreover, one obvious transgressive process that occurred in MIS3 may have been related to enhanced precipitation that was reportedly widespread in the west of China, while short-term fluctuations in the lake level might well be a direct response to regional precipitation variations on the millennial scale.
\end{abstract}

\section{Xingkai (Khanka) Lake, sand hills, OSL dating, 200 ka, environmental evolution of lake}

Citation: Zhu Y, Shen J, Lei G L, et al. Environmental evolution of Xingkai (Khanka) Lake since 200 ka by OSL dating of sand hills. Chinese Sci Bull, 2011, 56: 2604-2612, doi: 10.1007/s11434-011-4593-x

Northeast China is an area that is sensitive to global climate change, located in the mid-high latitude region that is affected by the East Asian Monsoon and the Polar Climate System and plays an important role in determining regional weather and climate patterns, as well as the general atmospheric circulation of the Northern Hemisphere [1,2]. Xingkai (Khanka) Lake, which is located in the eastern margin of Heilongjiang Province and crosses the Sino-Russia boundary, is the largest freshwater lake in Northeast Asia. Because of its key position, it is the only site in Northeast Asia for which there are global lake drilling points in the PAGES Pole-Equator-Pole Program [3]. Over the past twenty years, the Sanjiang Plain and Muling-Xingkai Plain

\footnotetext{
*Corresponding author (email: jishen@niglas.ac.cn)
}

on the north side of the lake have been studied for paleoenvironmental and peat purposes [4-7]. Additionally, drilling cores in Xingkai Lake have recently been progressively studied [8,9]. However, despite its climatic significance, there have been few studies conducted to investigate climatic evolution during the middle and late Pleistocene, which is beyond the limit of ${ }^{14} \mathrm{C}$ dating owing to the lack of suitable dating material. It is very important to study key ages in the evolutionary history of Xingkai Lake and surrounding plains since the middle Pleistocene using other material and methods.

Xingkai Lake is surrounded by mountains to the west, south and northeast, and by plains to the north and east. Additionally, there are four sand hills located on the north side of the lake. The formation and preservation of sand 
hills, which provide indispensable information for comparison with the record from drilling cores, are closely related to the lake evolution process. The formation and development of the plain in the northern part of Xingkai Lake have been studied [10] based on three discontinuous thermoluminescence datings from sand hills and fluvial deposits collected in the 1980s [11]. However, owing to the limitations associated with the dating quantity and method, there have been few detailed and accurate datings that can be compared with the latest research results. The optically stimulated luminescence (OSL) dating technique has become a useful tool for both experimental techniques and applications [12-14], and its reliability for dating has been confirmed by comparison with ${ }^{14} \mathrm{C}$ datings $[15,16]$. As a result, OSL has been widely applied for Quaternary sediments using the single aliquot regenerative-dose (SAR) protocol [17-19]. Therefore, OSL is a suitable tool to date samples collected from sand hills. Here, we attempt to conduct a systematic chronological study of sand hills using the OSL method to understand the evolutionary history of Xingkai Lake, which is important to understanding the relationship among lakes, climate and environment in Northeast China, as well as the climatic patterns between regional environmental change and global climatic changes.

\section{Study area and materials}

Xingkai Lake $\left(44^{\circ} 32^{\prime}-45^{\circ} 21^{\prime} \mathrm{N}, 131^{\circ} 58^{\prime}-132^{\circ} 51^{\prime} \mathrm{E}\right)$ is located in an inter basin in the Ussuri-Khanka Depression (Figure
1). The lake has a surface area of $\sim 4380 \mathrm{~km}^{2}$, with an average elevation of around $69 \mathrm{~m}$. The average water depth is 4-5 m, with a maximum water depth of $\sim 10 \mathrm{~m}$. As a trough fault lake in the Dunhua-Mishan fault zone, the catchment of the lake is primarily covered by Quaternary sediments composed of $300 \mathrm{~m}$ diluvial and alluvial sediments. The Komissarovka, Mel'gunovka, Ilistaya and Spasovka rivers in Russia and the Baileng River in China are the main inflows. Xingkai Lake is in a typical sub humid continental monsoon climate system, with a mean annual temperature of $2.9-3.1^{\circ} \mathrm{C}$. The highest monthly average temperature occurs in July $\left(\sim 21^{\circ} \mathrm{C}\right)$ and the lowest in January (approximately $-18^{\circ} \mathrm{C}$ ). The annual precipitation in the study area is 554-690 $\mathrm{mm}$ and the annual evaporation reaches $\sim 490 \mathrm{~mm}$. Southwest winds prevail in spring- summer, while northwest winds prevail in autumn-winter.

There are four sand hills located on a plain on the north side of Xingkai Lake in parallel concentric arcs with the lake shoreline. The hills are known as Dahu Hill, Taiyang Hill, Er' dao Hill and Huang-Nan Hill in sequence from the lake shoreline. The hills have different widths (30-200 m), lengths $(20-80 \mathrm{~km})$ and heights $(3-10 \mathrm{~m})$. Based on a field survey conducted in October 2009, we investigated six typical sites, D1 and D2 from Dahu Hill, T1 from Taiyang Hill, E1 from Er' dao Hill and H1 and H2 from Huang-Nan Hill (Figures 1 and 2). Analysis of the lithological features showed that the soil-forming layer and plow layer on the top part of the hills were obviously different from those below the sand layer (known as "sand hill" in previous studies [10, 11]) besides of Dahu Hill. In addition, there was a section of

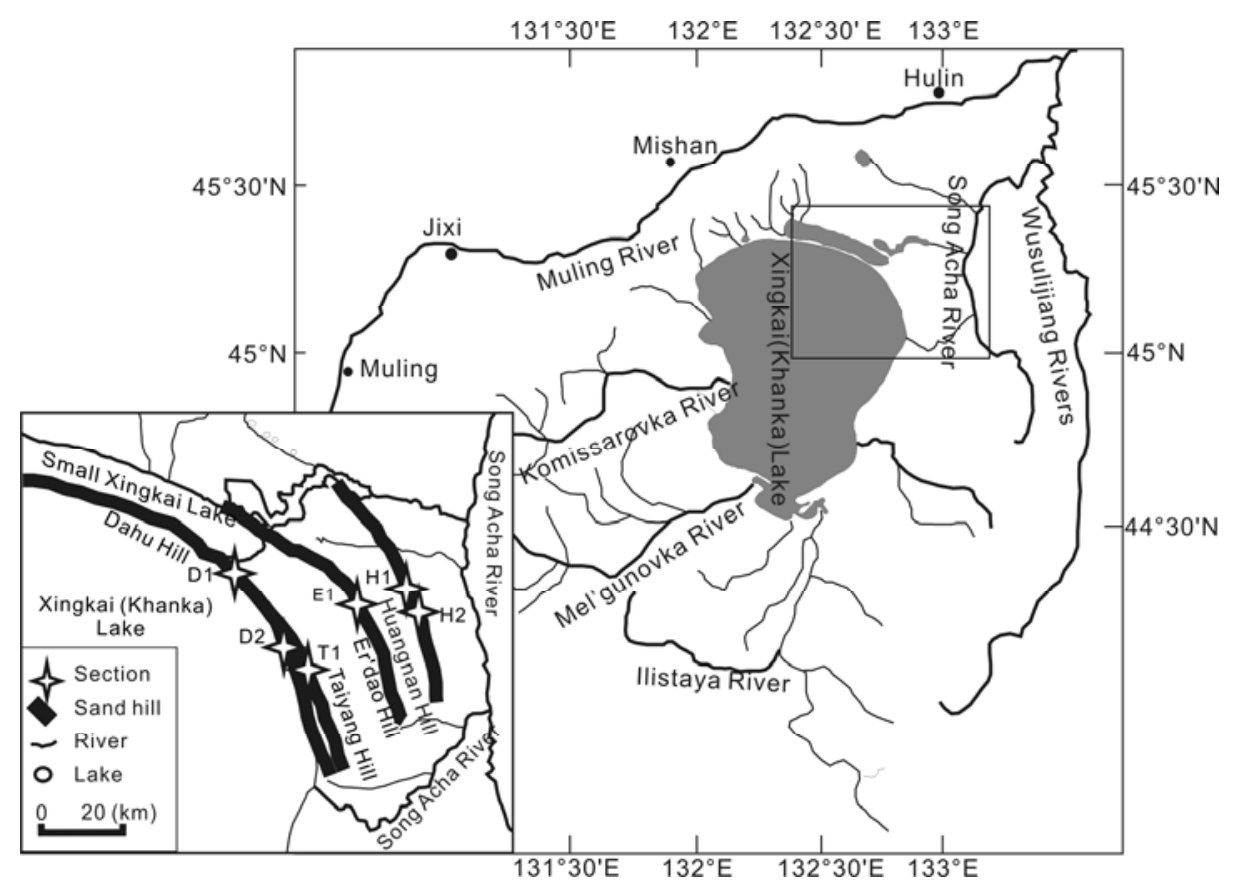

Figure 1 Location of sand hills of Xingkai Lake and the sampling locations. 

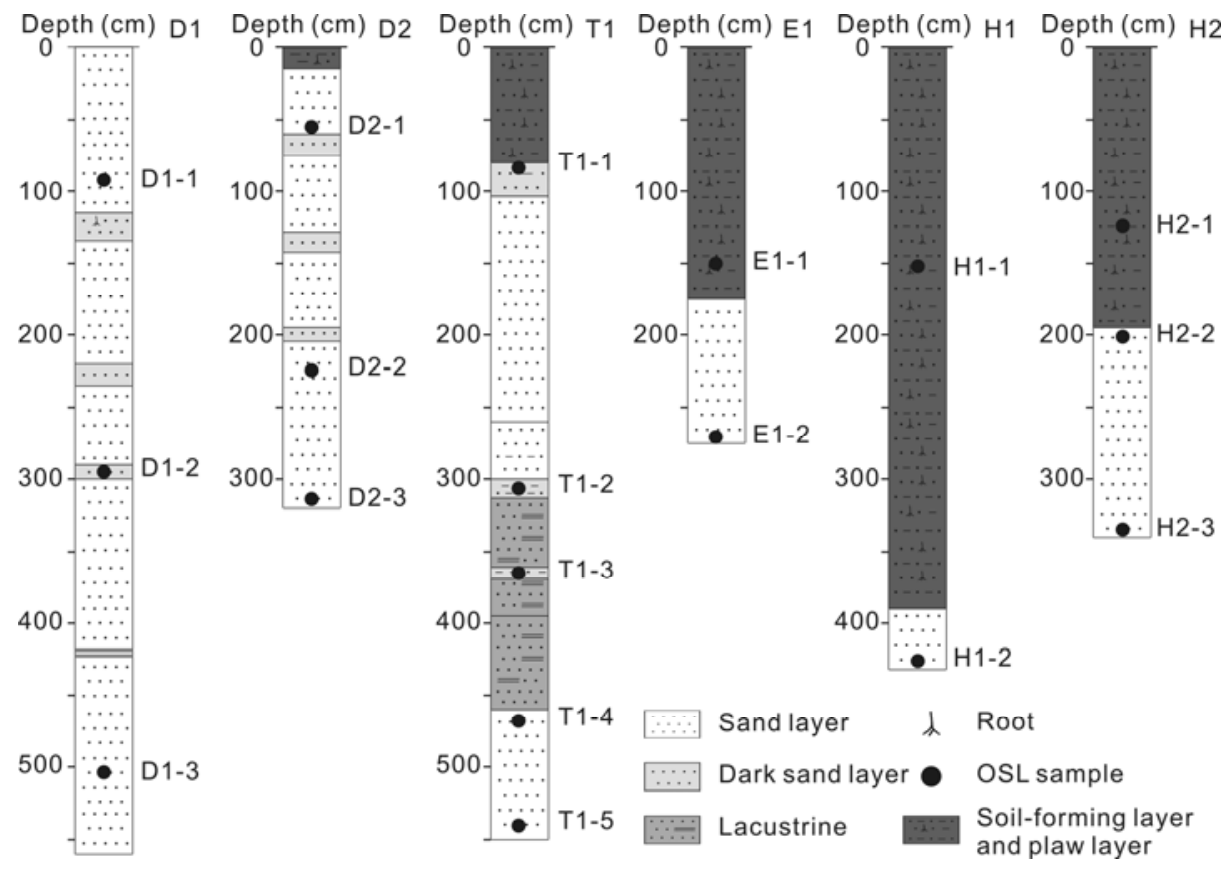

Figure 2 Lithology of each sand hill section.

lacustrine deposits with obvious horizontal bedding in the sand layer of Taiyang Hill and several darker bands were observed in the sand layer of Dahu Hill and Taiyang Hill.

All samples were obtained by hammering steel tubes into cleaned vertical outcrop sections. The tubes were then covered with aluminum foil and immediately placed in black bags. A total of 18 OSL samples were collected on sections of sand hills (Figure 2). In addition, samples for other experiments based on lithological features were obtained at intervals of $5-20 \mathrm{~cm}$.

\section{Methods}

In the laboratory, sample preparation was conducted under safelights $(\lambda=640 \pm 10 \mathrm{~nm})$. Two size fractions (fine: 4-11 $\mu \mathrm{m}$, and coarse: $90-125 \mu \mathrm{m})$ of quartz grains were used for dating. The fine grains fraction $(4-11 \mu \mathrm{m})$ was prepared as follows: grains less than $83 \mu \mathrm{m}$ (based on 180 sieving) were treated with $\mathrm{HCl}(40 \%)$ and $\mathrm{H}_{2} \mathrm{O}_{2}(30 \%)$ to remove carbonates and organics, after which they were treated with $30 \% \mathrm{H}_{2} \mathrm{SiF}_{6}$ for three days. Samples were then washed in distilled water until they reached $\mathrm{pH} 7$, at which time the 4-11 $\mu \mathrm{m}$ fractions were collected in accordance with Stoke's Law. The samples were subsequently dried and deposited on stainless steel disks (diameter $=1 \mathrm{~cm}$ ) at lower temperature $\left(40^{\circ} \mathrm{C}\right)$. For the coarse fraction, grains of 90-125 $\mu \mathrm{m}$ were separated by slow sieving in water. An electronic magnet was then used to remove magnetic minerals. Next, the samples were treated with $40 \%$ HF for one hour to remove feldspars and the alpha-irradiated outer layer of quartz grains, after which the samples were washed with distilled water several times. The resulting quartz grains were subsequently dried under low temperature. Finally, pure quartz grains were deposited on stainless steel disks using silicone oil. The purity of the quartz was then checked by IR stimulation.

OSL measurements were conducted at the Luminescence Dating Laboratory of the Groundwater Mineral Water and Environmental Supervising and Testing Center, located in Shijiazhang. All measurements were made using a Daybreak 2200 automated OSL reader equipped with a combined blue $(470 \pm 5 \mathrm{~nm})$ and infrared $(880 \pm 80 \mathrm{~nm})$ LED unit. Samples were pretreated by heating at $260^{\circ} \mathrm{C}$ for $10 \mathrm{~s}$, after which the heat was reduced to $220^{\circ} \mathrm{C}$ for $10 \mathrm{~s}$. Luminescence emissions for all samples were detected by $801 \mathrm{E}$ detection. The estimated ratio for irradiation was 0.103871 Gy/s. The $\mathrm{U}$ and Th contents were measured by neutron activation analysis, while the $\mathrm{K}$ content was measured by atomic absorption spectrophotometry. The environmental dose rate was estimated using the method described by Fleming [20].

The grain size and magnetic susceptibility were measured at the State Key Laboratory of Lake Science and Environment of Nanjing Institute of Geography and Limnology, Chinese Academy of Sciences. For gain size, carbonate and organic carbon were removed by treatment with excess $\mathrm{HCl}$ and $\mathrm{H}_{2} \mathrm{O}_{2}$. The final residue was treated with $\left(\mathrm{NaPO}_{3}\right)_{6}$ as a dispersant and then scanned using a microscope. Grain-size analysis was conducted using a Malvern 2000 instrument with a measurement range of $0.02-2000 \mu \mathrm{m}$. The magnetic susceptibility (MS) was measured using a Bartington $\mathrm{MS}_{2} \mathrm{~B}$ (both $4.7 \mathrm{kHz}$ and $0.47 \mathrm{kHz}$ ) loop core scanning sensor. 


\section{Discussion}

\subsection{Formation and controlling factors of sand hills}

The grain size of the sand hills is primarily composed of fine sand fractions with diameters ranging from $1.8 \Phi$ to 2.4 $\Phi$, and the content of silty sand and clay is less than $5 \%$. The sediments are well-sorted with single peak characteristics based on the frequency curves of typical samples. Figure 3 shows the $C-M$ plot of all samples and the probability cumulative curve of some typical samples.

Probability cumulative curves reflect different transportation states (lapse, jump and suspension) and dynamic characteristics of transporting [21]. In the present study, the probability cumulative curves of typical samples were found to have characteristics basically identical to samples. The grains were primarily distributed from $0.5 \Phi$ to $4 \Phi$, and were well sorted with a high content fraction of saltation (more than 98\%). The $C-M$ plot indicated the maximum kinetic energy and average kinetic energy of sediment transport. The grains of most samples are plotted in the cross area of $C(300-1000 \mu \mathrm{m})$ and $M(200-500 \mu \mathrm{m})$, indicating that the transport process is controlled by a single strong energy dynamic.

Analysis of the grain-size proxies showed that sand sediments of the sand hills were sea (lake) beach eolian deposits with a typical eolian character. Sand hills were primarily formed by wind transportation and accumulation [21]. In addition, the sediments had smooth and well-rounded surfaces that were produced by the movement of lake-waves. These findings indicate that when Xingkai Lake was stable, coarse sands and fine sands in the lake were transferred to the beach by waves and deposited 200-300 m off shore by wind. The sand hills then formed gradually by continued accumulation in a prolonged geological period. This process can currently be observed directly on the lakeshore when there are strong winds, and is the key factor responsible for the distribution of the hills in a smoothing curvature arc around the lake [22].

The formation and development history of sand hills are closely related to the evolutionary process of Xingkai Lake. Specifically, sufficient sediment material transferred by inflows is beneficial for the formation of sand hills during the early stages of lake-spread episodes [23]. Moreover, the increasing accumulation of sand hills depends on there being a relatively stable lake level, with longer periods of stability being associated with larger sand hills. Additionally, sand hills can be destroyed by erosion and transportation of lake-waves during later expansion. Finally, sand hills will stop developing owing to increased distance from the material source with the beginning of large-scale regression. Therefore, it can be inferred that sand hills formed in the period of sustainable and stable lacustrine transgression, then stopped accumulating and were preserved after a large-scale regression.

In addition to Dahu Hill, which is currently developing, the soil-forming layer and plow layer on the top of other hills showed obvious differences in lithology with sand layers. The proxies of grain size and magnetic susceptibility showed that the average median diameter of all samples in the sand layer was $2.1 \Phi$ and the magnetic susceptibility was $0.5 \times 10^{-8} \mathrm{~m}^{3} \mathrm{~kg}^{-1}$; however, higher values of $5.2 \Phi$ and $2.9 \times 10^{-8} \mathrm{~m}^{3} \mathrm{~kg}^{-1}$ were observed for grain size and magnetic susceptibility, respectively, in the soil-forming layer and the plow layer. The sand layer was formed by wind and waves during the initial stages. After depression, the accumulation process stopped, and the soil-forming and plow deposition began to develop as markers of the transgression ending, and the preservation of the sand hills indicated that no greater transgressions occurred later. Therefore, changes in the level of Xingkai Lake can be determined based on the lithology and changes in the grain size and magnetic susceptibility of the sand hills.

In addition, the short-term lake water level fluctuation can also have an important effect on the lithology of the
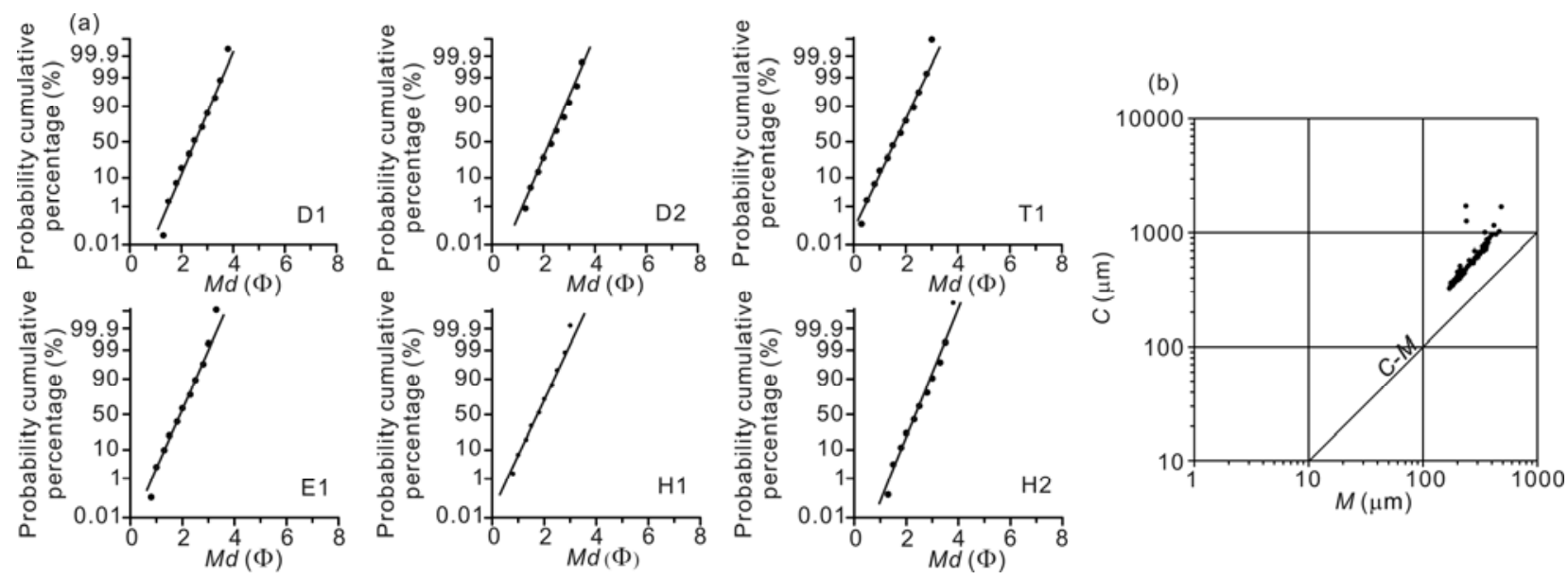

Figure 3 The $C$ - $M$ plot of all samples and probability cumulative curve of typical samples of sections from sand hills. 
sand hills. For example, relatively coarse sediment was deposited on sand hills because the transportation distance decreased when short-term transgressions occurred. However, short term depressions likely favored the accumulation of fine grains. Such periods have been recorded by environmental indices (such as grain size and magnetic susceptibility) owing to the reworking and pedogenic processes of local plants.

\subsection{Age of sand hill accumulation}

In an OSL experiment, the simplified multiple aliquot regenerative-dose (SMAR) protocol and single aliquot regenerative-dose (SAR) protocol were used to determine the

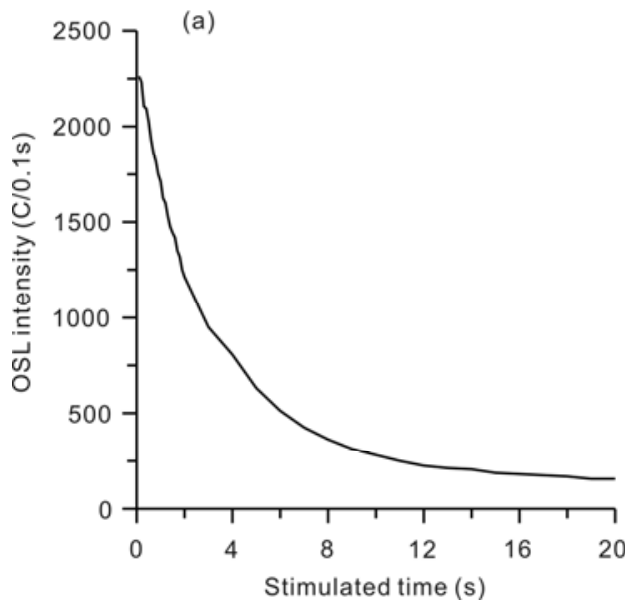

equivalent dose (De) for fine grain samples [24] and for coarse quartz samples [25], respectively. OSL decay curves and growth curves for sample T1-3 are shown in Figure 4. The OSL signal decreases very quickly in the first few seconds (Figure 4(a)), and the growth curve can be well fitted using the exponential plus the linear form (Figure 4(b)), indicating that the OSL signal is dominated by a fast component and the SMAR protocol is appropriate for dating [26]. De distributions measured by the SAR protocol showed a tight normal distribution for most samples, with a range of repetitious measurement ratios below 5\%, suggesting that the samples were well bleached prior to deposition [27]. Based on OSL measurements, the dose rates and OSL ages for the sand hills are shown in Table 1.

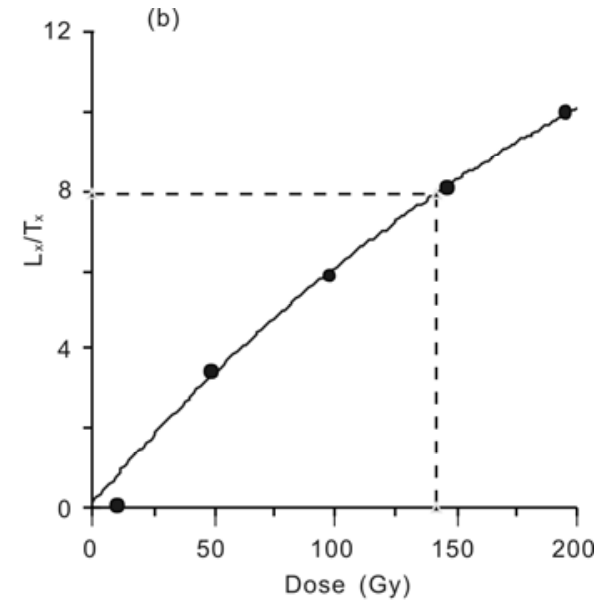

Figure 4 Attenuation curve (a) and growth curve (b) of sample T1-3.

Table 1 Environmental radioactivity, dose rate and OSL ages determined from sand hills

\begin{tabular}{|c|c|c|c|c|c|c|c|c|}
\hline Sample & $\begin{array}{l}\text { Depth } \\
(\mathrm{cm})\end{array}$ & $\begin{array}{c}\mathrm{U} \\
\left(\mu \mathrm{g} \mathrm{g}^{-1}\right)\end{array}$ & $\begin{array}{c}\text { Th } \\
\left(\mu \mathrm{g} \mathrm{g}^{-1}\right)\end{array}$ & $\begin{array}{c}\mathrm{K} \\
(\%) \\
\end{array}$ & $\begin{array}{c}\text { Equivalent dose } \\
(\mathrm{Gy})\end{array}$ & $\begin{array}{c}\text { Annual dose } \\
(\mathrm{Gy} / \mathrm{ka})\end{array}$ & $\begin{array}{c}\text { Water content } \\
(\%) \\
\end{array}$ & $\begin{array}{l}\text { Age } \\
(\mathrm{ka})\end{array}$ \\
\hline D1-1 & 85 & 0.4 & 2.08 & 2.89 & $2.32 \pm 0.22$ & 3.79 & 1.98 & $0.7 \pm 0.1$ \\
\hline D1-2 & 295 & 0.4 & 1.79 & 2.97 & $7.82 \pm 0.19$ & 3.42 & 4.74 & $2.3 \pm 0.1$ \\
\hline D1-3 & 495 & 0.39 & 1.72 & 2.88 & $9.24 \pm 0.44$ & 3.19 & 5.69 & $2.9 \pm 0.1$ \\
\hline D2-1 & 57 & 0.41 & 1.87 & 2.96 & $3.23 \pm 0.12$ & 3.42 & 2.65 & $0.9 \pm 0$ \\
\hline D2-2 & 227 & 0.38 & 1.69 & 2.88 & $5.2 \pm 0.42$ & 3.24 & 5.41 & $1.6 \pm 0.1$ \\
\hline D2-3 & 317 & 0.34 & 1.21 & 2.48 & $5.72 \pm 0.48$ & 2.80 & 3.50 & $2.0 \pm 0.2$ \\
\hline $\mathrm{T} 1-1$ & 97 & 0.38 & 1.68 & 3.34 & $62.49 \pm 3.63$ & 3.85 & 3.07 & $16.2 \pm 1.1$ \\
\hline $\mathrm{T} 1-2$ & 307 & 0.82 & 3.07 & 2.71 & $82.49 \pm 2.63$ & 3.40 & 6.44 & $24.2 \pm 1.2$ \\
\hline $\mathrm{T} 1-3$ & 370 & 0.4 & 2.25 & 3.04 & $100.41 \pm 1.73$ & 3.59 & 2.01 & $28.0 \pm 1.2$ \\
\hline $\mathrm{T} 1-4$ & 462 & 0.75 & 2.74 & 3.13 & $143.1 \pm 3.01$ & 3.81 & 3.06 & $37.6 \pm 1.3$ \\
\hline $\mathrm{T} 1-5$ & 547 & 0.43 & 1.74 & 3.08 & $163.75 \pm 3.6$ & 3.43 & 4.40 & $47.7 \pm 2.2$ \\
\hline E1-2 & 257 & 1.26 & 5.96 & 2.45 & $483.18 \pm 20.25$ & 3.58 & 5.11 & $135.0 \pm 7.8$ \\
\hline H1-1 & 152 & 1.6 & 4.66 & 2.06 & $424.14 \pm 16.08$ & 3.12 & 11.10 & $135.9 \pm 9.1$ \\
\hline H1-2 & 425 & 0.68 & 4.25 & 2.2 & $509.57 \pm 17.29$ & 2.59 & 19.43 & $183.8 \pm 9.6$ \\
\hline $\mathrm{H} 2-1$ & 127 & 0.86 & 4 & 2.16 & $479.48 \pm 13.6$ & 2.95 & 9.37 & $162.7 \pm 7.7$ \\
\hline $\mathrm{H} 2-2$ & 182 & 0.77 & 3.43 & 2.22 & $501.9 \pm 13.06$ & 2.73 & 20.57 & $183.8 \pm 8.8$ \\
\hline $\mathrm{H} 2-3$ & 312 & 0.66 & 2.18 & 2.39 & $568.55 \pm 4.45$ & 2.96 & 4.52 & $191.9 \pm 7.8$ \\
\hline
\end{tabular}


Based on field geological investigations, all sections of sand hills were continuous, and no obvious sedimentary interruption or erosion was observed for any sections. Based on the OSL datings, the age increased with depth in a stratigraphical order (Table 1), indicating stable deposition. Using interpolation and extension methods, an age model was constructed for all profiles. The datings for profiles D1, D2, $\mathrm{T} 1$ and $\mathrm{H} 2$ were relatively dense. To calculate the sediment accumulation rates (SAR), we used linear interpolations between the two ages and extrapolated the SAR toward the lithological boundaries where no dating existed, and the final chronology of the sections was obtained based on the SAR. The results showed that the age of the sand layer in profile $\mathrm{H} 2$ ranged from 193.0 to $183.6 \mathrm{ka}$, the age of T1 was 23.8-14.5 ka, while that of D1 was from $3.1 \mathrm{ka}$ to the present and the age of D2 was from $2.0 \mathrm{ka}$ to the present. For section E1, which had few datings, the mean SAR of the sand layer was calculated as the sediment accumulation rate of whole sections. The results revealed that the age of the sand layer on E1 ranged from 136.1 ka to 130.4 ka. For profile $\mathrm{H} 1$, there was only one dating for the sand layer, which prevented construction of the chronology. Considering the un-reversed datings and larger dating error for older ages, the age of the sand layer of $\mathrm{H} 1$ was estimated to be around $183.8 \mathrm{ka}$. These findings agreed with the age of $\mathrm{H} 2$, which was close to that of $\mathrm{H} 1$.

The obvious difference between the sand layer and top sediment observed upon analysis of the lithology was indicated by the environment environmental proxies of grain size and magnetic susceptibility, and provide strong evidence of a change in the sediment environment. Because the soil-forming layer and plow layer started to develop at the beginning of the regression, the time at which accumulation of the hills stopped was the same as the age of the soil-forming layer and the point at which the plow layer developed. Although there were a few datings at the bottom of the sand layers, considering the rapid sediment accumulation rate, a rough age was estimated for all hills based on six sections. Huang-Nan Hill primarily developed during 193-183 ka, while Er'dao Hill was formed at 136-130 ka, Taiyang Hill formed at 24-15 ka and Dahu Hill developed at around $3 \mathrm{ka}$.

\subsection{The evolutionary history of Xingkai Lake since 200 ka and the control factors}

The formation and development of sand hills on the northeast side of Xingkai Lake were closely related to the lake evolution. The evolutionary history of Xingkai Lake was rebuilt based on OSL datings and the results of previous studies conducted in the Ussuri-Khanka depression of Primorye [28]. The results revealed a regressive stepwise trend that included at least four transgressions (during 193-183 ka, 136-130 ka, 24-15 ka and since $3 \mathrm{ka}$ ) and three depressions. The detailed process was as follows. (1) At around $200 \mathrm{ka}$,
Xingkai Lake had a much larger surface area than at present day and the north shoreline remained along Huangnan Hill for a long time. At the same time, geological data recorded from the Ilistaya and Mel'gunovka Rivers showed that a conjoint limnic reservoir existed within the downstream reach [29]. Since $183 \mathrm{ka}$, Xingkai Lake has regressed rapidly, and the north shoreline has moved away from Huangnan Hill. (2) A lacustrine transgression occurred at about $136 \mathrm{ka}$ in the Ussuri-Khanka Depression [30], at which time the lakeshore line moved back to Er'dao Hill, where it stayed until another regression occurred at about $130 \mathrm{ka}$. Palynomorphs from the base of the silty sequence of the Nakhodka Horizon, which are an indicator of lake shoaling, suggested a gradual transition from landscapes of dark coniferous taiga to broad-leaved forest of the Manchurian type [28]. During 130-25 ka, Xingkai Lake did not pass beyond Er'dao Hill, although there were several stages in which the shoreline fluctuated on the north side based on previous studies. For example, a higher sand content and a bed of quartz-feldspar beach sand with well-rounded gravel and pebbles in the core were deposited on the coastal shoals, close to the Mel'gunovka River estuary, which marked a new short-term transgression [31]. In the northern part of the basin, this regression was accompanied by the emergence of a spacious lowland swamp [29]. Owing to the destruction by the larger transgression that occurred later, there was little evidence of this transgression remaining on the land. (3) From about $24 \mathrm{ka}$, Xingkai Lake extended, with Taiyang Hill forming on the north and northeast side. This period marked a powerful transgression of Xingkai Lake, with a reported increase in the water level from 1.5 to $4.0 \mathrm{~m}$ above the present lake level [28]. In addition to the current rivers, the Belaya and Muling Ho rivers flowed into the lake at the east and west side, respectively [32]. During this transgression, a short period transgression was recorded by the sediment stratum, and the lake water then rapidly decreased. Following this regression, the Small Xingkai Lake formed on north side of Xingkai Lake. Since $15 \mathrm{ka}$, the lake-level started to fall, and this was accompanied by the accumulation of coarse-grained quartz-feldspar beach sands enriched with gravely material [33]. The last regressive process in this stage started at about 8.5-8.0 ka and ended at 3.2-2.8 ka, and resulted in nearly complete disappearance of the lake and draining of the surrounding plains. The maximum amplitude of this regression was observed in the southern portion and decreased from south to north in the basin. (4) Thereafter, the lake-level rose slowly and resulted primarily in swamping on the surrounding land areas since about $3 \mathrm{ka} \mathrm{[33].}$

Analysis of the stratigraphic characteristics and ages around Xingkai Lake clearly demonstrated that transgression of Xingkai Lake occurred during periods of relative climate cooling, while lake regression followed the start of the warm period since 200 ka (Figure 5). For example, during MIS2 and early and later MIS6, when the climate 


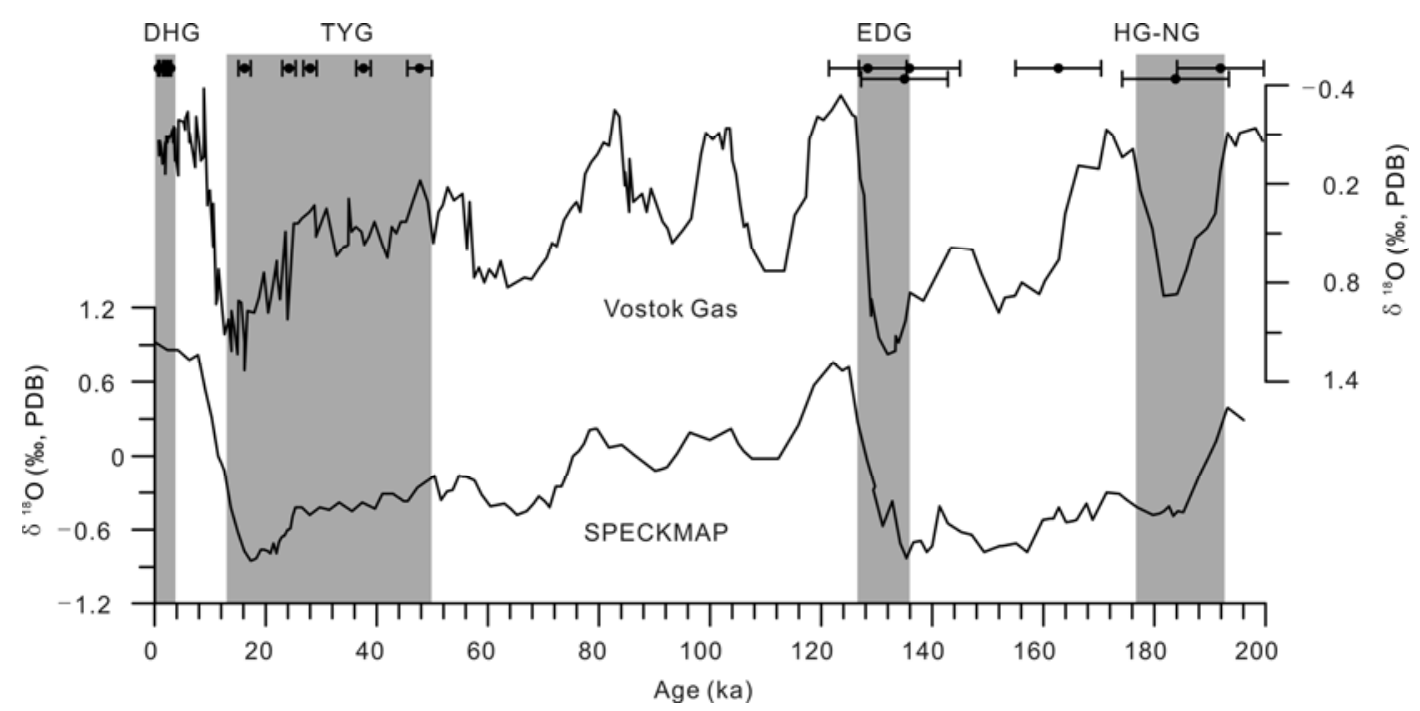

Figure 5 Comparison of the age of the sand hills of Xingkai Lake (dark columns: DHG for Dahu Hill, TYG for Taiyang Hill, EDG for Er'dao Hill and HG-NG for Huangnan Hill), atm- $\delta^{18} \mathrm{O}$ value of Vostok gas and $\delta^{18} \mathrm{O}$ value of SPECMAP.

was cool, lake transgression was present. These findings were confirmed by studies of the southern part of the Ussuri-Khanka depression [34]. As early as the middle of the Pleistocene, previous studies revealed that transgressions occurred when the climate was cool. For example, the pollen record of the central basin indicates that one transgression occurred during a cool period (Shmakovka time), and the water level decreased during the following warm period (Sungach time) [29,35]. Therefore, it can be inferred that this relationship started as early as the middle of the Pleistocene.

Xingkai Lake is a vast formation, and development of the lake depends primarily on the spatial distribution of fields, as well as the depression subsidence rate and alluvial accumulation rate. The effect of the depression subsidence rate since the middle Pleistocene can be ignored [30]. The stratigraphic position and ages of the lacustrine and lacustrine-palustrine sedimentation showed that the flat terrain in the Ussuri-Khanka depression played an important role in the transgression and regression of the lake. During the warm period, although precipitation would increase, water was discharged from the lake to the river because of enhanced stream trenching and headward erosion; therefore, the lake surface level usually showed a decreasing trend $[28,36]$. During the cool period, the lake level increased as the relative humidity increased because of the low temperature and low evaporation. Moreover, the annual river runoff was more uniform owing to the partial conservation of the precipitation in some perennial snowfields and permafrost areas [31]. Lake level oscillations also depended primarily on climatic factors based on present observations. Here, the OSL datings provided strong evidence of the changes in lake-level and climatic change.

In addition to the four large scale transgressions of Xingkai Lake recorded since $200 \mathrm{ka}$, a typical bed lake sedimentation was present in the sand layer of the Taiyang Hill profile, indicating a short-term expansion process. This process started at $37 \mathrm{ka}$, at which time the lake shoreline crossed Taiyang Hill; however, the shoreline did not arrive at Er'dao Hill in the north part of the lake until $25 \mathrm{ka}$, at which time the lake level had rapidly dropped. This transgression occurred during the period of later MIS3 and was different from other transgression stages that occurred during the cooling period. MIS3 was a special period in history, during which time large lakes and high lake levels were present in Tibet plateau and Northwest of China [37-39]. Shi et al. [40] called this period the High Temperature and Large Precipitation Event. According to the pollen record, transgressions occurred in the Bohai Sea, the Yangtze River Delta and the Zhujiang River Delta during this period [41]. Paleosoil formed in the Northern Mongolian Plateau followed by the Gobi regression [42]. Lake sediment or high lake level were also found for Konya Lake in the Arabian Desert during this period [43]. Shen et al. [44] showed that precipitation in northeastern China in MIS3a was 100-400 $\mathrm{mm}$ higher in MIS3a than during the present period. There is also a great deal of evidence that a wet period occurred in MIS3. This was mainly primarily caused by the particularly strong Indian monsoon that enhanced the cross equator air current from the southern hemisphere over the Indian Ocean, which was activated by high solar radiation of the precession cycle at low latitudes [45]. Therefore, it was deduced that the transgression that occurred around 37-25 ka was controlled by enhanced precipitation rather than temperature.

In addition to the long-term lake evolution, short-term water-level fluctuations were recorded by the grain size and magnetic susceptibility analysis (Figure 6). The two proxies showed a similar change in the profiles of Taiyang Hill and Dahu Hill. Based on these sediment records, several lake 

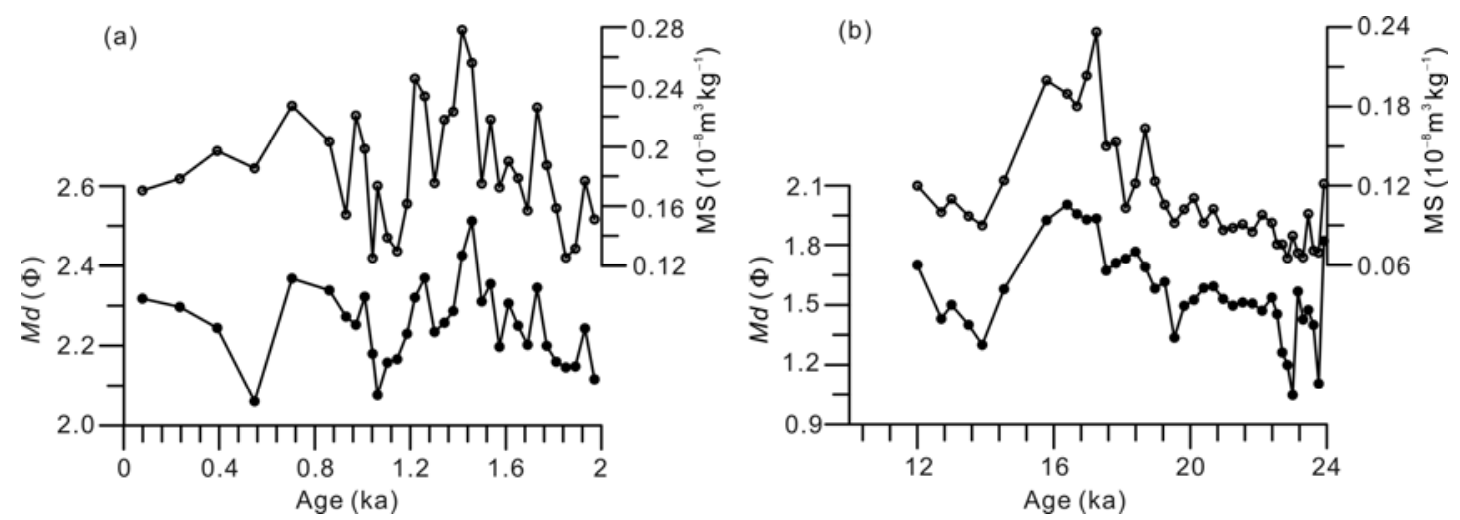

Figure 6 Grain size and magnetic susceptibility records of Dahu Hill (a) and Taiyang Hill (b).

retreating events were found. Specifically, the grains were fine and the magnetic susceptibility was high in the dark layer during $17.2-15.7 \mathrm{ka}$ in the profile of Taiyang Hill. A similar change in grain size and magnetic susceptibility was also observed in section D1 and D2 around $1.4 \mathrm{ka}$, which may indicate a short-term regression. These data were interpreted as follows: as the lake levels decreased in the short-term, the lake moved far away from the sand hill, at which time less coarse material moved to the hill and more fine material was deposited on top of the hill. This resulted in the value of magnetic susceptibility becoming larger because of the later pedogenic process. According to Asian monsoon records, the climate in the Asian monsoon area was dry during 17-15 ka, and it was reported that the development of desertification in north China was around 1.4 ka [46]. Therefore, the down water-level was resulted by the decreasing precipitation. Based on these findings, shortterm lake level fluctuations on the millennial scale were in response to regional variations in precipitation that were directly controlled by the Asian monsoon.

\section{Conclusions}

The environmental evolution of Xingkai Lake was rebuilt since $200 \mathrm{ka}$ based on the first-time systematic chronology study conducted by OSL dating and multiple index analysis of four sand hills on the north side of Xingkai Lake.

The development of four sand hills, which were formed by transportation and accumulation driven by lake-waves and wind, on the north plain of Xingkai Lake was closely related to the evolutionary history of the lake. Sand hills were deposited during the period of sustainable and stable lacustrine transgression and were preserved after depression. The 18 OSL dating data obtained from the sand hills together with multiple index analysis indicates that the north shoreline of Xingkai Lake retreated to the south in a stepwise fashion at least four transgressions (during 193-183 ka, 136-130 ka, 24-15 ka and since $3 \mathrm{ka}$ ) and three depressions since $200 \mathrm{ka}$.
The transgressive stages were concurrent with the epochs of climate cooling, whereas the periods of regression corresponded to climatic optima since the middle Pleistocene, and these were caused by changes in the alluvial accumulation intensity in the Ussuri River Valley and variations of regional temperature and humidity. In addition, one great transgression occurred in MIS3 may have been related to enhanced precipitation rather than temperature that was reportedly widespread in the west of China, and short-term lake level fluctuations on the millennial scale (such as $15 \mathrm{ka}$ and $1.4 \mathrm{ka}$ ) occurred in response to regional precipitation variations.

We thank Profs. Zhao Hua and Wang Chengmin for the OSL measurement. Special thanks are given to the editors and reviewers for their constructive advice. This work was supported by the National Natural Science Foundation of China (40872117).

1 An Z S, Porter S C, Kutzbach J E, et al. Asynchronous Holocene optimum of the East Asian monsoon. Quat Sci Rev, 2000, 19: 743-762

2 Li W Y. Quaternary Vegetation and Environment of China (in Chinese). Beijing: Science Press, 1998

3 Williams D F, Kuzmin M I, Prokopenko A A, et al. The lake Baikal drilling project in the context of a global lake drilling initiative. Quat Int, 2001, 80-81: 3-18

4 Qiu S W, Jiang P, Li F H, et al. Preliminary study on the environmental evolution in eastern China since the late Ice Age (in Chinese). Acta Geogr Sin, 1981, 36: 315-327

5 Xia Y M, Wang P F. Peat record of climate change sincce 3000 years in Yangmu, Mishan region (in Chinese). Geogr Res, 2000, 19: 53-59

6 Yang Y X, Wang S Y. Study on mire development and paleoenvironment change since $8.0 \mathrm{ka}$ BP in the northern part of the Sanjiang plain (in Chinese). Sci Geogr Sin, 2003, 23: 32-38

7 Zhang S Q, Deng W, Yan M H, et al. Pollen record and forming process of the peatland in Late Holocene in the north bank of the Xingkai Lake, China (in Chinese). Wetland Sci, 2004, 2: 110-115

$8 \mathrm{Wu}$ J, Shen J. Paleoenvieonmental and paleocimatic changes reflected by diffuse reflectance spectroscopy and magnetic susceptibility from Xingkai: Lake sediments (in Chinese). Mar Geol Quat Geol, 2009, 29: 123-130

9 Wu J, Shen J. Paleoclimate evolution since $27.7 \mathrm{ka}$ BP reflected by grain size variation of a sediment core from Lake Xingkai, northeastern Asia (in Chinese). J Lake Sci, 2010, 22: 110-118

10 Qiu S W, Wan E P, Li F H, et al. Development of the plain in the north of the Xingkai Lake and formation of its wetlands (in Chinese). 
Wetland Sci, 2007, 5: 153-158

11 Qiu S W, Wan E P, Wang P F. Coastline changes of the Xingkai Lake and discovery of ancient source of Song' acha river (in Chinese). Chinese Sci Bull, 1988, 12: 937-940

12 Wintle A G. Luminescence dating: Laboratory procedures and protocols. Radiat Meas, 1997, 27: 769-817

13 Prescott J R, Robertson G B. Sediment dating by luminescence: A review. Radiat Meas, 1997, 27: 893-922

14 Zhao H, Lu Y C, Chen J, et al. IRSL and GLSL dating of fine grain from late quaternary sediments in North China (in Chinese). Chinese Sci Bull, 2000, 45: 2332-2337

15 Huntley D J, Hutton H T, Prescott J R. The standed beach-dune sequence of south-east South Australia: A test of thermoluminescence dating, 0-800 ka. Quat Sci Rev, 1993, 12: 1-20

16 Zhao H, Lu Y C, Wang C M, et al. Optical dating of Holocene water-laid sediments recorded hydrological environmental changes in the Oasis of Shulehe river alluvial fan in Gansu Province (in Chinese). Nucl Tech, 2007, 30: 893-898

17 Long H, Lai Z P, Wang N A, et al. Holocene climate variations from Zhuyeze terminal lake records in East Asian monsoon margin in arid northern China. Quat Res, 2010, 74: 46-56

18 Yang L H, Zhou J, Lai Z P, et al. Lateglacial and Holocene dune evolution in the Horqin dunefield of northeastern China based on luminescence dating. Palaeogeogr Palaeoclimatol Palaeoecol, 2010, 296: 44-51

19 Lu H Y, Thomas S, Yi S W, et al. An erosional hiatus in Chinese loess sequences revealed by closely spaced optical dating (in Chinese). Chinese Sci Bull, 2006, 51: 2767-2772

20 Prescott J R, Robertson G B. Sediment dating by luminescence: A review. Radiat Meas, 1997, 27: 893-922

21 Shanbei Team of Chengdu Geological College. Grain-size Analysis and Its Applications of Sedimentary Rocks (in Chinese). Beijing: Geological Publishing House, 1976

$22 \mathrm{Hu}$ J S. Sand hills and its cause of Xingkai Lake (in Chinese). Heilongjiang Geol, 2001, 12: 89-95

23 Wang K C, Chen G M. On the formation of Xingkai Lake (in Chinese). Heilongjiang Sci Tech Water Conserv, 2005, 4: 52-53

24 Wang X L, Lu Y C, Li X N. Progress in luminescence dating of Chinese loess by Single-aliquot Regenerative-dose (SAR) protocol (in Chinese). Nucl Tech, 2005, 28: 383-387

25 Murray A S, Wintle A G. Luminescence dating of quartz using an improved single-aliquot regenerative-dose protocol. Radiat Meas, 2000, 32: 57-73

26 Roberts H M, Duller G A T. Standardised growth curves for optical dating of sediment using multiple-grain aliquots. Radiat Meas, 2004, 38: $241-252$

27 Olley J M, Caitcheon G G, Roberts R G. The origin of dose distributions in fluvial sediments, and the prospect of dating single grains from fluvial deposits using optically stimulated luminescence. Radiat Meas, 1999, 30: 207-217

28 Korotkii A M, Grebennikova T A, Karaulova L P, et al. Lacustrine transgressions in the late Cenozoic Ussuri-Khanka depression (Pri- mor'e). Russian J Pacific Geol, 2007, 1: 53-68

29 Korotkii A M, Karaulova L P, Romashkova N I. Lacustrine transgressions and late Cenozoic sedimentationin Ussuri-Khanka depression (in Russian). Geol-Geomor Conf Compl Far East, 1980, $162-181$

30 Korotkii A M, Kitaev I V, Mikhailove N A, et al. Lithological characteristics of modern sediments in lake Khanka (in Russian). Sed Form Petrol-Bearing Areas Far East, 1975, 78-96

31 Korotkii A M. Lake types and Quaternary limnogenesis in the southern far east. Paleoclimatol Paleolimnol Paleoecol, 2000, 4: 106-125

32 Korotkii A M, Karaulova L P, Alekseeva E V, et al. On finding the Khorol'sky mammoth (Primorye) (in Russian). Evol Environ, 1981: 29-50

33 Bazarova V B, Mokhova L M, Orlova L A, et al. Variation of the lake Khanka level in the late Holocene. Russian J Pacific Geol, 2008, 23: $272-276$

34 Bersenev I I, Sokhin V K. Quaternary deposits (in Russian). Geol USSR, 1969, 32: 373-389

35 Pavlyutkin B I, Khanchuk A I. New data on the age of lake Khanka, the Russian far east. Earth Sci, 2002, 383: 187-189

36 Korotkii A M. Relationship between tectonic and climatic factors during the late Cenozoic evolution of river valleys in the Sikhote Alin and southwestern Primorye (in Russian). Evol River Valleys Lands Reclam, 1979: 29-35

37 Zhao X T, Zhu D G, Yan F H, et al. Climatic change and lake level variation of Nam Co, Xizang since the Last Interglacial Stage (in Chinese). Quat Sci, 2003, 23: 41-52

38 Yang X P, Liu D S. Palaeoenvironments in desert regions of northwest China around $30 \mathrm{kaBP}$ (in Chinese). Quat Sci, 2003, 23: 25-30

39 Zhang H C, Lei G L, Chang F Q, et al. Age determination of the shell bar section in salt lake Qarhan, Qaidam basin (in Chinese). Quat Sci, 2007, 27: 511-521

40 Shi Y F, Jia Y L, Yu G, et al. Features, impacts and causes of the high temperature and large precipitation event in the Tibetan Plateau and its adjacent area during 40-30 ka BP (in Chinese). Lake Sci, 2002, 14: $1-11$

41 Zheng Z, Wang J H. Paleoenvironmental significance of late quaternary pollen flora in Northern Zhujiang River Delta (in Chinese). Tropic Oceanol, 1998, 17: 1-9

42 Feng Z D. Gobi dynamics in the Northern Mongolian Plateau during the past 20000+ yr: Preliminary results. Quat Int, 2001, 76: 77-83

43 Roberts N, Erol O, de Meester T, et al. Radiocarbon chronology of the late Pleistocene Konya lake, Turkey. Nature, 1979, 281: 662-664

44 Shen H Y, Zhang Y M, Jia Y L. An organic carbon isotopic record from sediment of the Huangqihai lake, Inner Mongolia: Implications of environmental evolution (in Chinese). Mar Geol Quat Geol, 2005, 25: $35-40$

45 Zhao K, Kong X G, Cheng $\mathrm{H}$, et al. Intensity and timing of D-O events of East Asian Monsoon during the late episode of MIS 3 (in Chinese). Quat Sci, 2008, 28: 177-183

46 Li Z P, Yue L P, Guo L, et al. Holocene climate change and desertification in northern China (in Chinese). Northwestern Geol, 2007, 40: 1-29

Open Access This article is distributed under the terms of the Creative Commons Attribution License which permits any use, distribution, and reproduction in any medium, provided the original author(s) and source are credited. 